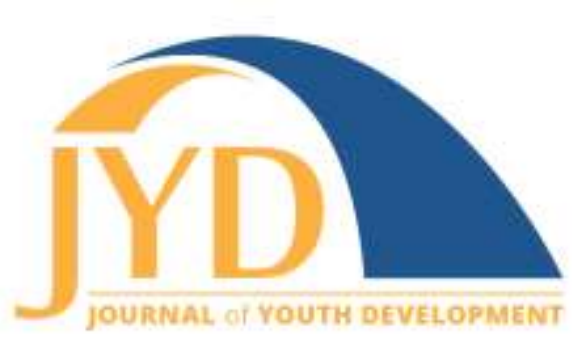

http://jyd.pitt.edu/ | Vol. 12 Issue 1 DOI 10.5195/jyd.2017.479 | ISSN 2325-4017 (online)

\title{
Reflection Circles: Professional Development and Accountability for Youth Workers
}

\author{
Shaina Beth Abraham \\ shaina.abraham@gmail.com
}

\begin{abstract}
This article explores how to support Youth Workers and ensure accountability through the use of reflection circles. Youth Workers report having a higher sense of responsibility in their work than is often required of them. This article proposes a model that includes youth, youth workers, employers, intermediaries, and funders in a process to strengthen the abilities of all youth workers. A holistic approach to supporting Youth Workers through reflection circles will ensure they are getting the support they need to improve and continuing to build their sense of responsibility, replacing the need for traditional accountability systems.
\end{abstract}

\section{Introduction}

As youth workers, one of our greatest professional strengths is the ability to adapt and change to a range of needs, while building relationships and collaborating with young people in a variety of settings. This strength is countered by the unique challenge of accountability. How do we maintain one of our greatest strengths without creating a system of accountability that diminishes it? It's important to ask this question because traditional accountability systems in similar fields such as social work and education, have been bogged down by attempts to demonstrate accountability, making it difficult for many practitioners to do the quality work that drew them to the field.

There are many complications with creating a typical accountability system for youth work. Three areas stand out as important aspects to consider. First the diversity of the field, from the many types of youth work happening to the varied paths people take to find the field, make the field stronger. Second, standards, even with the best intentions, can lead to complacency and lack of understanding as to the reason for the standard. Finally, youth workers report having a

\footnotetext{
(cc) EY New articles in this journal are licensed under a Creative Commons Attribution 4.0 License. This journal is published by the University Library System, University of Pittsburgh and is cosponsored by the University of Pittsburgh Press. The Journal of Youth Development is the official peer-reviewed publication of the National Association of Extension 4-H Agents and the National AfterSchool Association.
} 


\section{Reflection Circles: Professional Development}

higher sense of responsibility for the work they do than is required of them. We don't want to lose this internal responsibility to the community because we created a substandard accountability system that hinders the good work being done.

\section{Background Information}

Throughout this article I define a traditional accountability system as a system created to define and monitor quality programming, including creation of standards, review of programs to monitor standard expectations, and credentialing for staff involved in programming. This process is almost always organized and implemented by an outside organization and commissioned by funders and government entities; youth workers or the people doing the work are not often represented in the process.

In researching how youth work maintains its flexibility while creating a system of accountability I interviewed six youth program managers or directors about the roles internal motivation and personal responsibility play in youth work; what drew them to the field and what motivation they see in the staff they supervise. Throughout my research, I reflected on my own experience as a youth worker and program manager. I have worked for large national organizations and very small nonprofits, and participated in the American Camping Association's accreditation process along the way. Most recently, I worked for a small nonprofit that wasn't always equipped with the resources to provide consistent, high quality training for all staff. I also used the experiences of my co-workers to help me develop my thoughts and ideas on the topic of accountability and youth work.

The experiences of people working in large and small organizations vary significantly with regard to staff development, and as a result their careers in youth work are affected differently by the size of their organizations. Though we try to provide adequate training and support for our staff, this is an area that many small youth-serving nonprofits struggle to prioritize due to limited or restricted funds.

\section{Diversity of the Field}

One aspect of youth work that helps it be responsive to the community is its diversity-the variety of programs and opportunities for young people, the unique ways staff find their way to youth work, and the diversity of youth workers themselves. The world of youth work isn't just after-school programs, tutoring or leadership development; it is also summer camps, homeless 


\section{Reflection Circles: Professional Development}

street outreach, organized sports and so on. Carol Thomas from the Minnesota Department of Education describes it well as a "beautiful mess" (personal communication, March 30, 2012). Creating a traditional accountability system that could incorporate all of the aspects of good youth work and adapt to the myriad of unique delivery models would be extremely complicated and would likely leave out many aspects of the positive youth work happening.

In addition to the diversity of ways youth work is happening, we need to embrace how youth workers find their way to the field. Both the formal and informal paths followed by youth workers to their chosen line of work are unique for each youth worker. According to Dana Fusco (2012) "There are three types of institutions designing and implementing formal YoED (youth worker education): Youth organizations, intermediary agencies (profit and nonprofit), and institutions of higher education. YoEd also occurs informally through peer networks, direct (onthe-job) training, experience, reflection and inquiry" (p. 10). This description doesn't include the former teachers, youth participants, park and recreation staff and those trained in other disciplines who join the field. This diversity of thought and perspective is an asset to the field and the communities it serves. Creating a traditional accountability system for youth work, may limit these unique paths to the field by requiring all staff to come from a similar background through credentialing. We lose the variety of experiences in the field and limit access to those who may not be able to afford the credential, or realize youth work as a possible career path until they have finished their education in a different field.

Limiting who has access to becoming a youth worker, could limit the racial and ethnic diversity of the field. In her exploration of this topic in 2012, Kari Denissen Cunnien noted, "It was feared that credentialing or licensing (these terms were used interchangeably by youth workers in listening sessions) would lead to a "whitening" of the field and that youth workers of color and/or from low-income backgrounds would have significantly greater access barriers to the field than white and/or higher-income individuals." (Denissen Cunnien 2012) The racial and ethnic background of youth workers matters because representation matters. We have seen a push in the media to create content that better represents all citizens, and this same representation is essential for our programs.

In a post on culturally responsive teaching, Laura Thomas (2016) states, "Indeed, representation matters, because 'If she can see it, she can be it.' Our children's early experiences--including the hours spent consuming media--shape what they imagine to be possible for people who look like them, live where they live, or come from where they came 


\section{Reflection Circles: Professional Development}

from. Simply put, kids determine what they can be based on the examples around them" (para. 3). Having role models and people you can count on who come from a similar place and have similar experiences helps young people see themselves as successful. If we limit who can join the field, we are limiting our success as a whole.

\section{Problem with Standards}

The creation of standards, competencies and certifications offers its own challenges when considering a system of accountability in youth work. Standards create knowledge nuggets or sound bites of information that lack the context to understand why the information is important. Over time, the high quality nature of the standard is lost, becoming an endpoint for youth workers to meet rather than a demonstration of the minimum standard of practice. Complacency of practice happens when there is a lack of dialogue and reflection. Over time the standard--typically average, rather than exceptional--becomes the high water mark that needs

to be met without question of why or a desire to do better. Credentialing for youth workers may have a similar result. What happens five years after the credentialing process? Over time, without continued dialogue and review, credentialing becomes a piece of paper in a drawer. Without follow-up training or support, credentialing is an endpoint that no longer supports the ongoing growth of the youth worker.

As a supervisor, I have stopped using competencies when training new staff and instead required them to read original works written by leaders in the field, including Gisela Konopka, Tony Jeffs, Mark Smith and others. I ask staff member to read an article and then, as a group, we discuss how we can apply this knowledge to our everyday work with the youth in our programs. Over the years of implementing this practice, I have seen a better understanding among direct-service staff members about why we organize our programs the way we do than when we simply gave them a list of guiding values. A traditional accountability system does not necessarily allow for continued growth, and can result in complacency.

Professional credentialing isn't the only accountability measure that can cause complacency. A standard alone is only a directive of what to do, not an understanding of why. Program accreditation processes neglect to provide context and rationale behind the standard, which can lead to misunderstanding among staff members if they are not trained adequately. For example, in its After School and Youth Development accreditation standards, the Council on Accreditation states Standard 5, "Promoting Positive Behavior and Healthy Peer Relationships" as follows: 


\section{Reflection Circles: Professional Development}

5.01 Rules and Behavioral Expectations:

a. set clear and appropriate limits;

b. are developed with children and youth enrolled in the program;

c. are conveyed and enforced in a fair, consistent manner.

Not only does this directive give no understanding or explanation for the standard, there is also no mention in the standards as to why we want youth involved in creating the rules and how to accomplish this. Well trained youth workers know that inclusion creates a sense of belonging, shared understanding of purpose, and makes the young people a part of the process, and they know how to include youth in the process. A program could become accredited by following this standard without understanding why it is important or how to implement it.

\section{Internal Responsibility}

Youth workers have high standards for their own for their work, often beyond what is required by their employer or a funder. All six of the program managers I interviewed gave examples of this. I remember working with a young staff person who questioned why we were asking youth about their school work, if we weren't going to follow up the conversation with the support they needed. He too, in his first year of work, wanted to do what was best for the youth, which was more than was required by our funding source. Because traditional accountability systems ignore motivation we risk losing highly dedicated youth workers who care about their work and young people by bogging them down with what can feel like arbitrary rules and requirements.

Five of the six program managers I interviewed reported having higher standards for themselves than what was expected of them by their supervisors. They also reported trying to instill a strong sense of responsibility in the new youth workers they hired. "We are responsible to the youth and our community and then to our funders" (Youth Program Manager, personal communication, April 16, 2012). Traditional accountability systems look at numbers and best practices, not personal responsibility or internal motivation. Losing the internal motivation of youth workers because we are focusing on the standards involved with an accountability system and not what the community needs would be a major loss to the field.

Youth workers want support from their employers and funders to do good youth work. A traditional accountability system would only create more busy work for staff without creating the support they want and need. We know the quality of a youth program depends on what staff do with youth (Walker and Gran, 2010). If we ignore the training needs of staff and create 


\section{Reflection Circles: Professional Development}

a system that doesn't educate them, we are alienating our most valuable resource in providing high quality programming for young people. Any accountability system we use should focus on youth worker support and education as a means of strengthening programs, not create competencies and standards that could lead to youth worker complacency and lack of interest in the work.

\section{An Alternative Accountability Approach}

As a response to the growing desire in the field to create accountability, I suggest we focus our time, efforts and resources on developing a model that convenes reflection circles for youth workers with various levels of experience. A model that accommodates the many stages and responsibilities of youth workers and those who supervise or support youth workers could impact the field by creating a new type of accountability and responsibility to each other and the communities we serve. Rather than being motivated by a set of standards, we would create a field driven by excellence and community needs. We don't need to define accountability for youth work using old frameworks; instead we can and should create a new model that is beneficial to youth workers.

A model using reflection circles would incorporate many of the best practices we have learned over the years in helping youth workers develop their skills and values. We know from research that formal education does not automatically create or result in high quality practice. Systems that support and encourage reflection help develop youth workers as they hone their skills and values. This model would provide support to youth workers who may not be able to afford higher education, while offering everyone the opportunity to learn from each other's experiences.

We know from previous research that using reflection-based approaches to learning youth development concepts is very successful (Walker and Walker, 2012). Experience as a supervisor has also taught me that "typical" staff development approaches to youth development trainings sometimes result only in pieces of knowledge being transmitted and not necessarily in producing better youth workers.

What youth workers do with our young people requires professional judgment and practical wisdom that transcends routine application of established rules and procedures or mechanical skills. As a field, we need professional development 


\section{Reflection Circles: Professional Development}

that accounts for the complex reality and artistry of everyday youth work practice. (Walker and Gran, 2010, p. 4)

Using reflection circles through a year-long experience that happens multiple times throughout a youth worker's career could be an answer or response to Walker and Gran's directive. Reflection circles would allow participants time to reflect about their own passions, values and goals related to their work and the opportunity to challenge themselves and see if their values are still aligned with the work they are doing. Participants would be able to learn about and from their colleagues' struggles while helping to develop their understanding of their goals and values for the work. Throughout the reflection process, youth workers could connect themselves better to their work and develop a stronger sense of self in how they approach youth work or how to better supervise novice youth workers. Having an opportunity to reflect and look at research would also help youth workers reconnect with why they joined the field in the first place and rekindle or stoke the fire that burned in them when they began their work with young people.

Reflection circles would not only benefit direct service youth workers, but would also create an important space for supervisors who rarely have the opportunity to connect with peers. Many youth worker supervisors I have spoken with wished they had a better support system when they were new youth workers and again as a supervisor of youth workers. "I supervise all the other youth workers in the building; my peers at work don't have the same struggles as me. I would love a place to learn from and reflect with my youth work peers." (Youth Program Manager, personal communication, March 8, 2012)

People who are excited about their work do better work (Ayers, 2005). Youth workers who are motivated to do good work will feel responsible to the youth and the communities they work in and, in turn, will do high quality work. By allowing time to reflect with their peers, youth workers themselves will create a new level of accountability in the field based on doing what is best, not what is expected. Reflection provides a space for new ideas and creative approaches to problems or dilemmas. By providing youth workers with regular access to reflection circles we are encouraging them to be creative and find solutions to issues or problems we may not have even known existed.

Creating a basic model for reflection circles would need to include some key ingredients and objectives. (See Figure 1.) 
Figure 1. Key Ingredients and Objectives for a Basic Reflection Model

$\begin{array}{ll}\text { Ingredients } & \text { Objectives } \\ \text { - Funder support-financial and } & \text { - A safe space for reflection } \\ \text { philosophical } & \text { - Opportunities to challenge research } \\ \text { - Required participation at least once } & \text { - Time to discuss practice dilemmas } \\ \text { every } 5 \text { years } & \text { - A place to ask for support } \\ \text { - camilar experience levels or place in } & \text { - Learn new approaches to the work } \\ \text { - Facilitation by a youth work professional } & \text { - Learn about commonalities of struggles } \\ \text { - who is not a participant in the group } & \text { Gevelop professional colleagues } \\ \text { - Revolving topics based on current trends } & \\ \text { and youth worker experience } & \end{array}$

\section{Role of Stakeholders}

To create a system of reflection circles that supports youth workers strengthens the field and leads to better opportunities for young people, we will need to include many stakeholders in the process: funders, intermediaries, employers/supervisors, youth workers, and youth. Ideally this model would replace the call for an accountability system, which means all these stakeholders need to be involved. Each stakeholder plays a critical role in ensuring a system of support and growth is created.

- Funders provide the financial and philosophical support to make the circles happen through an intermediary. Potentially, funders could also provide incentives to organizations that use the system regularly.

- Intermediaries are responsible for executing the model, including planning, implementing and evaluating. An important distinction here is that the intermediary cannot also be a funder, this separation is important to the integrity of the circle for participants.

- Organizations and supervisors must encourage and/or require staff to participate.

On top of allowing participation, supervisors should support staff during their participation, including but not limited to dedicating time in staffs' schedules and reflecting with them about the process while they are participating. 


\section{Reflection Circles: Professional Development}

- Youth workers need to participate regularly, at least once every 4 or 5 years, and again within 1 to 2 years if their responsibilities increase.

- Youth inform the intermediary facilitators of any concerns or topics that they believe would help the youth worker support them better.

By involving a variety of stakeholders we can ensure that reflection circles have the support needed to reach our anticipated results.

\section{Anticipated Results}

How do reflection circles eliminate the need for outside accountability systems? The quick answer is they don't. There will always be a need for program evaluation, quality assessment, and staff development opportunities. Reflection circles allow us an additional opportunity to engage youth workers and feed their high sense of responsibility to the work. They also provide support that keeps youth workers motivated, provides connection to their peers and research, pushes their understanding of the field, and solidifies the impact the field can have on communities. Using outcome-driven processes such as credentialing, youth worker certification, or program accreditation doesn't fit the field. Youth work is about the process; we should have a system designed to help youth workers through their process to strengthen their work.

As a result of youth workers' participation in reflection circles we could expect to see many positive results in the field. Participants would be more engaged with their job and excited to do good youth work, which, in turn, would keep them in the field longer. Almost all youth work supervisors have struggled with retaining quality staff for long periods of time. Longer tenure results in more qualified staff; less time spent orienting new staff; and longer, stronger relationships with young people. This continuity with young people leads to better outcomes for the youth involved and results in a stronger field.

Youth work, as a field, is lucky to have such a wide array of experiences and expertise. Building reflection circles into our regular development would allow us access to each other's experiences and expertise. Through this reflective work, youth workers would be able to learn from the unique perspectives of their colleagues who work in diverse areas, and create solutions they might not have been able to envision without access to youth workers doing different styles of work. 


\section{Reflection Circles: Professional Development}

A more connected field could also result from reflection circles. By working closely with youth workers from other organizations during reflection circles, youth workers will expand their network for support and develop partnerships across organizations that will benefit youth, communities and organizations. For example, staff from the agency where I worked built relationships with staff from another organization. Our services were complementary, and through partnership and cross-referrals we were able to ensure that youth from both programs had basic needs support as well as social activities. The connection between the organizations was developed by staff from both, and benefited the youth by finding the resources and opportunities each needed. By combining time and meaningful learning through reflection circles, youth workers would naturally build connections and be better prepared to serve their communities and connect with others when they need assistance.

While building these connections, we would also be building the strength of the youth work workforce. I have been lucky enough in my career to have supervisors who saw their role as more than just a supervisor; they all believed it is important to help me develop skills to either continue to help the organization and community I was working for, or to go to another organization and use my skills there. By creating reflection circles that connect youth workers to research, practice, other areas of the youth work field and self-reflection, we are better preparing them to do the work they value. Not all organizations have the capacity to truly support individual growth of youth workers. Having a funder-supported network of reflection circles would help develop strong individual youth workers and support the field overall.

Reflection at work is an important element of program quality and staff success. One of the trickiest areas of being a youth work supervisor is creating a space where youth workers feel safe and supported without fear their jobs are on the line if they make a mistake. Even if they have a great relationship with their supervisor, they may not feel comfortable processing a mistake with them. By creating reflection circles away from the organization, we could support youth workers in asking tough questions and process events that they might be afraid to bring up with their supervisors.

An initiative that is supported and facilitated by funders, intermediaries, and employers might initially seem unsafe to a youth worker who would like to open up and ask critical questions about his or her own practice. For this reflection practice to be successful, it is vital that youth workers know they can reflect and ask questions without employment repercussions. The facilitator will need to be skilled at developing trust among the group. While there are some 


\section{Reflection Circles: Professional Development}

instances when a facilitator may need to report back to a supervisor, most mistakes, as long as they are being addressed by the youth worker, can be kept within the group. Building positive relationships between supervisors and employees takes time. Having staff and supervisors who are practiced in reflection, would help improve those relationships. As youth workers build confidence in their abilities they will be more likely to share their issues with their supervisor. As a result of participation in reflection circles, youth workers will be less likely to make significant mistakes and more likely to reflect with their supervisor when they do.

Youth workers often enter the field excited and motivated to work while their core values for the work develop along the way. A system of reflection would help youth workers delve deeper into their own values and those of the youth workers who came before them. An important aspect of youth work is the ability to care. According to Mayeroff, (1972), in order to truly care for others we must participate in self-reflection to understand who we are and what we bring to the caring relationship. Our values as caring adults are what guide us as we work with young people. Having a space to reflect and develop our knowledge throughout our careers helps us become a better field and create more caring environments for young people.

\section{Conclusion}

Reflection circles should not be the beginning or the end of a youth program accountability system. In partnership with funders, quality assessment, and program evaluation, reflection circles would become an integral part of strengthening the field. Youth workers will stay more connected and dedicated to their work, they will continue to work in the areas of the field in which they excel, and ultimately will prove to be better youth workers.

Supporting young people is what we do in youth work. "We spend all this time setting up learning opportunities for the youth, but we never think about doing it for ourselves." (Youth Worker, personal communication, January 27, 2012) Creating a system of accountability that doesn't include time for staff to reflect and reenergize would continue to ignore one of our field's greatest assets: youth workers.

\section{References}

Ayers, K. (2005, February). Creating a Responsible Workplace. HR Magazine, 50 (2). 
Council on Accreditation. (2017). After school and youth development. Retrieved January 10 2017, from Council on Accreditation: http://coanet.org/standard/cyd-ayd/5/

Denissen Cunnien, K. (2012). It's Complicated: Crafting a System to Support Youth Work. Retrieved from http://web.augsburg.edu/sabo/Walkabout/It's-Complicated.pdf

Fusco, D. (2012). Working in youth service organizations: The sphere of professional education. Minneapolis, MN: University of Minnesota, Extension Center for Youth Development.

Mayeroff, M. (1972). On Caring. New York, NY: HarperPerennial.

Thomas, L (2016). Edutopia: Why representation matters. Retrieved January 3, 2017. https://www.edutopia.org/blog/why-representation-matters-laura-thomas

Walker, K., \& Gran, C. (2010). Beyond Core Competencies: Practitioner Expertise as a Critical Component of Quality. Minneapolis, MN: University of Minnesota, Extension Center for Youth Development.

Walker, J., \& Walker, K. (2012). Establishing expertise in an emerging field. In D. Fusco (Ed.), Advancing youth work: Current trends, critical questions (pp. 39-51). New York, NY: Routledge 